Table 2 Physiological, haematological, and biochemical variables used in assessing prognosis in acute pancreatitis

\begin{tabular}{lll}
\hline Systolic hypotension & $<$ & $90 \mathrm{~mm} \mathrm{Hg}$ \\
Tachycardia & $<$ & 140 \\
Fever & $>$ & $38.4^{\circ} \mathrm{C}$ \\
Prothrombin time & $>$ & 14 seconds \\
White cell count & $<$ & $20 \times 10^{9} / 1$ \\
Haematocrit & $<$ & $30 \%$ \\
Serum albumin & $30 \mathrm{~g} / 1$ \\
Serum creatinine & $>$ & $0 \cdot 18 \mathrm{mmol} / 1$ \\
Serum urea & $>$ & $5 \mathrm{mmol} / 1$ \\
Serum bilirubin & $>$ & $69 \mathrm{mmol} / 1$ \\
Serum calcium & $<$ & $2 \mathrm{mmol} / 1$ \\
\hline
\end{tabular}

findings than the other indices studied, although Cassey's index is more likely to be completed. As has been stated above, indices requiring serial assays, or assays such as the $\mathrm{PaO}_{2}$ in arterial blood which are not routinely carried out on admission, were less likely to permit a complete assessment of the patient's condition.

Although undiagnosed pancreatitis is probably uncommon as a sole cause of death, the retrospective use of one or more of these indices may help assess the severity of the patient's condition on admission to hospital and in determining the contribution made towards a fatal outcome by the failure to diagnose and treat the acute pancreatitis.

1 Wilson C, Imrie CW. Deaths from acute pancreatitis: Why do we miss the diagnosis so frequently? Int J Pancreatol 1988;3:273-82.

2 Ranson JHC, Rifkend KM, Roses DF, Fink SD, Eng K, Spencer FC. Prognostic signs and role of operative management in acute pancreatitis. Surg Gynecol Obstet 1974;139:69-81.

3 Ranson JHC. Acute pancreatitis: Pathogenesis, outcome treatment. Clin Gastroenterol 1984;13:843-63.

4 Agarwal N, Pitchumoni CS. Simplified prognostic criteria in acute pancreatitis. Pancreas 1986;1:69-73.

5 Cassey JG, Clark DA. Predictors of severity of attacks of acute pancreatitis. Aust NZ J Surg 1986;56:887-9.

6 Osborne DH, Imrie CW, Carter DC. Biliary surgery in the same admission for gall stone associated acute pancreatitis. Br J Surg 1981;68:758-61.

7 Jacobs ML, Daggett WM, Civetta JM, et al. Acute pancreatitis: Analysis of factors influencing survival. $A n n$ Surg 1977;185:43-51.

8 Schuppiser JP, Grotzinger V, Van der Linden J. Helv Chir Acta 1984;51:661-3.

\title{
HLA antigens in Hungarian patients with idiopathic haemochromatosis
}

\author{
E Czìnk, E K Gyódi, K Német, S Hollán
}

National Institute of Haematology and Blood Transfusion Daroczi Unit 24, 1113 Budapest, Hungary E Czink

E K Gyódi

K Német

$S$ Hollán

Correspondence to:

Dr E Czink.

Accepted for publication 16 August 1990

\begin{abstract}
Thirteen unrelated patients with idiopathic haemochromatosis (eight men, five women) were studied. The diagnosis was based on clinical, biological, and histochemical findings. HLA typing was performed in all 13 and in all of their available first degree relatives $(n=31)$. HLA A3 was present in nine of 13 probands $(69.2 \%$ compared with $18.8 \%$ in the group of 53 healthy blood donors and $22.4 \%$ in a selected Hungarian population $(n=1910)$. HLA B7 was present in five of 13 probands (38.4\% compared with $11 \cdot 3 \%$ and $14 \cdot 6 \%$ ). An A3B7 antigen association was found in five of 13 patients. The A3B7 haplotype was found in three, A2B12 and A2B38 haplotypes were found twice in 10 genotyped probands. Pedigree studies showed that there was one unafiected homozygote, 24 heterozygotes, and six non-carriers.

Extended family and population studies are necessary to establish the prevalence of the gene in Hungary and an association with haplotypes other than A3B7.
\end{abstract}

Idiopathic haemochromatosis is a recessively transmitted hereditary disease that is characterised by generalised parenchymal iron overload, leading to liver cirrhosis, diabetes mellitus, cardiomyopathy, endocrine dysfunction, arthropathy and skin pigmentation. ${ }^{1}$ The idiopathic haemochromatosis gene is closely linked to the HLA-A locus on chromosome $6^{2}$; A3, B7, and B14 are most strongly associated with it. ${ }^{3}$ The HLA marker for the idiopathic haemochromatosis allele is, in fact, haplotypic. ${ }^{3}$ In a family where one member has idiopathic haemochromatosis the HLA identical sibling should also be affected. ${ }^{4}$

We collected data on HLA distribution in patients with idiopathic haemochromatosis in Hungary so that we could assess the number of affected family members in a given population.

\section{Methods}

Thirteen unrelated patients (eight men and five women) aged 35 to 65 years were studied. Idiopathic haemochromatosis was diagnosed on clinical, biochemical, and histochemical grounds. HLA typing was performed in 13 probands and in all of their available first degree relatives $(n=31)$ through pedigree studies. Relatives sharing both, one, or no HLA haplotypes with the proband were regarded as either homozygous, heterozygous for the idiopathic haemochromatosis gene, or normal (non-carriers). ${ }^{4}$ Determinations of serum iron, iron binding capacity, and serum 
Table 1 Clinical, biochemical, and histological data of 13 unrelated Hungarian subjects with idiopathic haemochromatosis

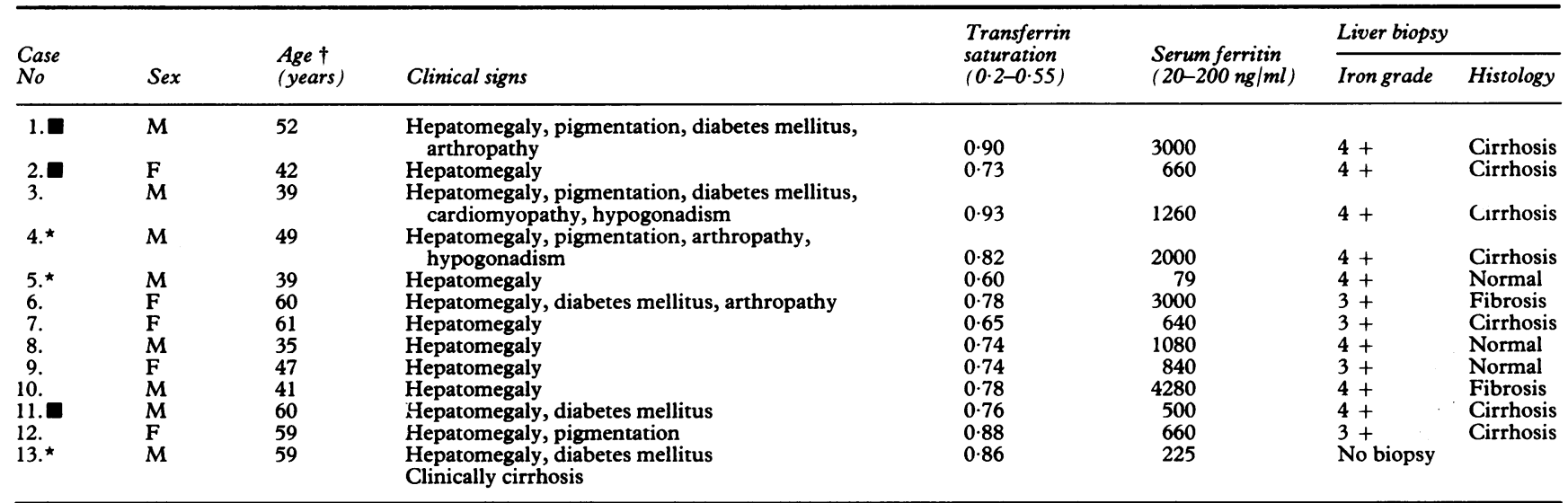

*Patients previously treated by phlebotomy.

$\dagger$ At the time of diagnosis.

The patient died after the study; the necropsy showed that he had had idiopathic haemochromatosis.

ferritin concentrations were carried out in all available family members and in 53 HLA typed blood donors who acted as controls. The HLA antigen distribution of the Hungarian population was determined by the HLA phenotype of healthy panel members, parents of patients waiting for organ transplantation, and couples involved in paternity testing, etc. The prevalence of HLA antigens in probands was compared with that of HLA antigens in the group of 53 healthy blood donors and in the Hungarian population ( $\mathrm{n}=$ 1910).

Serum iron concentrations and total iron binding capacity were determined using standard techniques; serum ferritin concentration was measured by a radioimmunoassay. Sections of liver biopsy specimens were stained with Perls's Prussian blue for iron for histochemical evaluation. Hepatic siderosis was graded according to Scheuer from 0 to $4+.5$ HLA typing was performed by the NIH lymphocyte cytotoxicity micromethod. ${ }^{6}$

\section{Results}

Table 1 shows the data on iron metabolism and the histological and clinical findings of each patient. In cases 1,2 , and 11 previous long term alcohol intake and exposure to insecticide sprays in case 12 were also aetiological factors in the formation of cirrhosis.

The prevalence of HLA antigens recorded in table 2 indicates that HLA A3 and B7 were more common in the patients with idiopathic haemochromatosis than in healthy blood donors or in the Hungarian population. HLA B14 was present in one patient. An association with HLA A3B7 was found in five of 13

Table 2 Prevalence of HLA antigens A3, B7, and B14 in patients with idiopathic haemochromatosis, healthy blood donors, and in a selected Hungarian population

\begin{tabular}{|c|c|c|c|c|c|c|}
\hline & $A 3$ & & $B 7$ & & $B 14$ & \\
\hline $\begin{array}{l}\text { Patients with IH }(n=13) \\
\text { Healthy blood donors }(n=53) \\
\text { Hungarian population }(n=1910)\end{array}$ & $\begin{array}{r}9 \\
10 \\
428\end{array}$ & $\begin{array}{l}(69 \cdot 2 \%) \\
(18 \cdot 8 \%) \\
(22 \cdot 4 \%)\end{array}$ & $\begin{array}{r}5 \\
6 \\
279\end{array}$ & $\begin{array}{l}(38 \cdot 4 \%) \\
(11 \cdot 3 \%) \\
(14 \cdot 6 \%)\end{array}$ & $\begin{array}{r}1 \\
2 \\
111\end{array}$ & $\begin{array}{l}(3.8 \%) \\
(5 \cdot 8 \%)\end{array}$ \\
\hline
\end{tabular}

patients. The genotypes of 10 of 13 unrelated probands and the phenotypes and genotypes of 31 first degree relatives were determined through pedigree studies. Twelve different haplotypes were found in 10 genotyped probands. The A3B7 haplotype was found three times, and $\mathrm{A} 2 \mathrm{~B} 12$ and $\mathrm{A} 2 \mathrm{~B} 38$ twice in seven of 10 probands. A3B7 was present in four of the seven children. Other haplotypes found once were: A1B8, A1B13, A1B38, A1B40, A2B15, A3B13, A3B27, A3B51, A3Bx, A11B7, A24B7, A24B12, and A32B12.

The pedigree analysis showed that there was one non-affected homozygote, who shared both proband's haplotypes. Transferrin saturation and serum ferritin concentrations were in the normal range $(0.34$ and $55 \mathrm{ng} / \mathrm{ml}$, respectively); the sibling of case 10 had died one year previously of idiopathic haemochromatosis. Six family members were noncarriers, while 24 persons were heterozygotes. Transferrin saturation values were in the normal range in all non-carriers and in all but two of 24 heterozygotes. These two heterozygotes had transferrin saturation repeatedly above $0 \cdot 70$, but the serum ferritin concentration was normal.

\section{Discussion}

The HLA antigens A3, B7, and B14 are most strongly associated with idiopathic haemochromatosis. ${ }^{3}$ In all reported series the HLA antigen $\mathrm{A} 3 \mathrm{had}$ a higher prevalence in patients with idiopathic haemochromatosis than in control subjects, ranging from $55 \%$ to $100 \%$ in idiopathic haemochromatosis, compared with $19 \%$ to $32 \%$ in control populations. ${ }^{7}$ The HLA antigen B7 also had an increased prevalence $(28-86 \%)$ in idiopathic haemochromatosis ( $v 9-34 \%$ ) in controls; as for antigen B14, about half the studies reported an increased prevalence in idiopathic haemochromatosis compared with controls. ${ }^{7}$

Our results show that HLA A3 is also closely associated with idiopathic haemochromatosis in Hungary. HLA A3 was present in $69.2 \%$ of cases of idiopathic haemochromatosis compared with $18.8 \%$ and 
$22.4 \%$ in controls. The prevalence of HLA B7 was also higher in idiopathic haemochromatosis than in controls $(38.4 \% v 11.3 \%$ and $14.6 \%$ ).

An association between the haemochromatosis gene and the A3B7 haplotype has been seen in all series throughout the world. ${ }^{3}$ Associations with $\mathrm{A} 3 \mathrm{~B} 14,{ }^{38} \mathrm{~A} 11 \mathrm{~B} 35$ and $\mathrm{A} 11 \mathrm{~B} 5{ }^{3}{ }^{3} \mathrm{~A} \mathrm{~B}^{8}{ }^{8}$ and $\mathrm{A} 3 \mathrm{~B} 35^{\circ}$ were also observed in different countries.

The association with A3B7 was observed in five probands of our series. The A3 antigen showed linkage with other $B$, not B7, antigens in four probands. In five probands with A3B7 phenotype pedigree analysis showed that only four of five genotypes accorded with the proband's genotypes.

Our results agree with data reported from other countries; A3 is significantly more common on idiopathic haemochromatosis chromosomes regardless of the presence or absence of B7 or B14, and A3 (and to a lesser degree A11) is the independent idiopathic haemochromatosis allele marker. ${ }^{3}$

The number of heterozygotes, identified through pedigree studies, agrees with the expected prevalence according to published findings, ${ }^{10}$ the number of homozygotes, however, was small. The probability of finding HLA identical (homozygote) family members through pedigree studies is influenced by different factors: the recessive mode of inheritance, the gene prevalence in the population, and number of siblings in the family, etc.

The HLA identical, but disease free sibling, was a 40 year old women with regular menses. The transferrin saturation value and the serum ferritin concentration were normal. She may be an example of incomplete expressivity or recombination. ${ }^{24} \mathrm{~A}$ detailed investigation of DNA polymorphism would be required to explain this finding. Extended family and population studies are necessary in Hungary to establish the prevalence of the gene and the likely role of haplotypes other than A3B7.

1 Powel LW, Basset ML, Halliday JW. Hemochromatosis: 1980 update. Gastroenterology 1980;78:374-81.

2 Powel LW, Ferluga J, Halliday JW, Basset ML, KohonenCorish M, Serjeantson S. Genetic hemochromatosis and HLA linkage. Hum Genet 1987;77:55-6.

3 Simon M, Le Mignon L, Fauchet R, et al. A study of 609 HLA haplotypes marking for hemochromatosis gene: (1) Mapping of the gene near HLA-A locus and characters required to define a heterozygous population; and (2) Hypothesis concerning the underlying cause of association. Am J Hum Genet 1987;41:89-105.

4 Edwards CQ, Cartwright GE, Skolnick MH, Amos DB. Homozygosity for hemochromatosis: clinical manifestations. Ann Intern Med 1980;93:519-25.

5 Scheuer PJ, Williams R, Muir AR. Hepatic pathology in relatives of patients with hemochromatosis. J Patho relatives of patients with
Bacteriol 1962;84:53-64.

6 NIH. NIAID Manual of tissue typing techniques 1976 1977. Washington DC: DHEW Publications (NIH) 1976: 75-545, 22-4.

7 Simon M, Fauchet R, Le Gall JY, Brissot P, Bourel $M$. Immunogenetics of idiopathic hemochromatosis and secondary iron overload. In: Nadir R Fareid, ed. Immunogenetics of endocrine Disorders. New York: Alan R Liss Inc, 1988:345-71.

8 Ritter B, Säfwenberg J, Olsson KS. HLA as a marker of the hemochromatosis gene in Sweden. Hum Genet 1984;68 62-6.

9 Piperno A, Fargion S, Panajotopoulos N, Ninno E, Del Taddei MT, Fiorelli G. Idiopathic haemochromatosis and HLA antigens in Italy: is A3Bw35 HLA haplotype a marker for idiopathic haemochromatosis gene in north marker for idiopathic haemochromatosis

10 Cartwright GE, Edwards CQ, Kravitz K, et al. Hereditary hemochromatosis. Phenotypic expression of the disease. N Engl J Med 1979;301:175-9.

\title{
Cytogenetic analysis of a granulocytic sarcoma in a patient without systemic leukaemia
}

\author{
L R Adam, B Angus, P Carey, E V Davison
}

Department of

Human Genetics,

University of

Newcastle upon Tyne

NE2 4AA

L R Adam

Department of

Pathology, University

of Newcastle upon

Tyne

B Angus

Department of

Haematology, Royal

Victoria Infirmary,

Newcastle upon Tyne

P Carey

Department of

Clinical Cytogenetics,

Birmingham

Maternity Hospital

E V Davison

Correspondence to:

L R Adam

Accepted for publication

26 July 1990

\begin{abstract}
Granulocytic sarcoma is a rare complication of leukaemia. Occasionally it presents before the development of systemic leukaemia when diagnosis may be difficult. A case of granulocytic sarcoma occurring in a patient with no overt evidence of leukaemia, but in whom cytogenetic analysis of the bone marrow showed a clonal $t(12 ; 13)$ translocation, is reported. Cytogenetic analysis of tissues in this disease may indicate evidence of systemic disease before overt morphological changes.
\end{abstract}

Granulocytic sarcoma is a rare tumour, defined as a "localised tumour mass composed of immature cells of the granulocytic series". The most common sites of presentation are bone, periosteum, soft tissue, lymph node and skin. The tumour may develop during the course of acute myeloblastic leukaemia (AML), chronic myeloid leukaemia (CML), or other myelodysplastic disorder. Alternatively, the tumour precedes leukaemia by some months. ${ }^{2}$ When granulocytic sarcoma presents without blood or bone marrow manifestations of leukaemia, the diagnosis may be missed. ${ }^{3}$ Histological diagnosis can be difficult and many patients are initially diagnosed as having high grade lymphoma. ${ }^{4-6}$ Often the first indication of misdiagnosis is the lack of response to treatment.

\section{Case report}

A 52 year old man presented with a rapidly enlarging chest wall mass, initially thought to be a high grade non-Hodgkin's lymphoma. Staging investigations showed no evidence of disease elsewhere and he was treated with 